\title{
SISTEM PAKAR KONSELING DAN PSIKOTERAPI MASALAH KEPRIBADIAN DRAMATIK MENGGUNAKAN METODE FORWARD CHAINING BERBASIS WEB
}

\author{
${ }^{1)}$ Januardi Nasir, ${ }^{2)}$ Jahro \\ Program Studi Teknik Informatika, Fakultas Teknik, Universitas Putera Batam, \\ Jalan R Soeprapto Tembesi, Batam, Indonesia \\ E-Mail : Januardinasir@gmail.com
}

\begin{abstract}
ABSTRAK
Diagnosa terjadinya masalah kepribadian dramatik pada seseorang yang didasarkan pada bentuk perilaku, mood, sosial interaksi, impulsif, dapat menjadi suatu hal yang kontroversial dan merugikan diri sendiri. Rendahnya fungsi interaksi sosial dilingkungan kerja, ikut memperburuk kondisi dan suasana emosi dengan cara mendramatisir, menyimpan erat, mengulang atau mengingat kembali suasana hati. Untuk membantu masyarakat yang menderita masalah kepribadian dramatik diperlukan alat bantu berbasis komputerisasi berupa Sistem Pakar yang dirancang dalam suatu program komputer untuk menentukan nilai ketidak pastian tersebut dan mempunyai kemampuan seperti seorang dokter. Sistem pakar ini menggunakan bahasa programan PHP dan MySQL sebagai basis datannya dengan metode forward chaining yang berbasis web dengan cara konsultasi dapat menjawab setiap pertanyaan dengan ya atau tidak, guna untuk mengetahui informasi mengenai gejala-gejala serta masalah kepribadian dramatik yang ada dan solusinya terapi untuk gejala tersebut.
\end{abstract}

Kata Kunci: Diagnosa Masalah Kepribadian Dramatik, Sistem Pakar, Forward chaining, Web

\section{ABSTRACT}

The diagnosis of a dramatic personality problem in a person based on behavioral, mood, social interaction, impulsive forms can be controversial and self-defeating. The low function of social interaction in the work environment, to exacerbate the condition and emotional atmosphere by dramatizing, keeping tight, repeating or recalling the mood. To help people who suffer from dramatic personality problems, computerized aids are needed in the form of Expert Systems designed in a computer program to determine the value of the uncertainty and have the ability as a doctor. This expert system uses the PHP and MySQL programming languages as its datanic basis with a web-based forward chaining method by consultation to answer any questions with yes or no, in order to find out information about the symptoms as well as the dramatic personality problems that exist and the solution of the therapy to the symptom the.

Keyword: Diagnose Problems of Dramatic Personality, Expert System, Forward Chaining, Web

\section{PENDAHULUAN}

Pada umumnya, Pada masa kanakkanak, Kepribadian sangat egosentris dan egoistis. Egosentris, artinya menjadikan diri sendiri sebagai titik pusat pemikiran (perbuatan) dan berpusat pada diri sendiri sedangkan egoistis artinya menilai sesuatu dan ukuran baik menurut dirinya sendiri. Dan selanjutnya pada akhir masa remaja, kepribadian egosentris dan egoistis tersebut akan berangsur-angsur berubah dan membentuk kepribadian yang lebih dewasa dan matang. Dalam beberapa kasus, kemungkinan seseorang tidak menyadari bahwa mereka memiliki masalah kepribadian dramatik (Asahar Johar1, Pudji Hartuti2 \& 1, 2, 2014)

Menurut (Asahar Johar1, Pudji Hartuti2 \& 1, 2, 2014) Masalah kepribadian dramatik adalah suatu gangguan berat dalam konsitusi karakterologis dan kecendrungan prilaku dari individu, biasanya meliputi beberapa bidang dari kepribadian dan hampir selalu berhubungan dengan kekacauan pribadi dan sosial. Sehingga seseorang dikategorikan mengalami masalah kepribadian dramatik. Dimana gangguan tersebut merupakan gangguan antisosial. Diagnosa terjadinya masalah kepribadian pada seseorang yang 
didasarkan pada bentuk perilaku, mood, sosial interaksi, impulsif, dapat menjadi suatu hal yang kontroversial dan merugikan diri sendiri. Kemunculan masalah kepribadian berawal dari stres, stres dapat memberikan imbas yang buruk, baik bagi kesehatan emosional maupun fisik, serta membuat kehidupan sehari-hari yang dijalani kurang menyenangkan.

Gangguan ini merupakan kelompok gangguan yang sangat heterogen, diberi kode aksi II dalam DMS dan dianggap sebagai pola perilaku dan pengalaman internal yang bertahan lama, pervasif (pola perilaku klien yang relatif tidak ringan tetapi secara signifikan mempengaruhi kehidupan klien sepanjang masa hidupnya, dan tidak fleksibel yang menyimpang dari ekspektasi budaya orang yang bersangkutan dan menyebabkan hendaya dalam keberfungsian sosial dan bekerja (Taufik, 2014).

\section{Definisi Sistem Pakar (Expert System)}

Menurut (Sutojo.T, Mulyanto, Edy, Suhartono, 2011, p. 159) Sistem pakar mulai dikembangkan pada pertengahan 1960, sistem pakar yang muncul pertama kali adalah General-purpose problem solver (GPS) yang dikembangkan oleh Simon. Sampai saat ini sudah banyak sistem pakar yang buat, seperti MYCIN untuk diagnosa penyakit, DENDRAL untuk mengidentifikasi struktur molekul campuran yang tidak dikenal, $X C O N$ \& XSEL untuk membantu konfigurasi sistem komputer besar, SOPHIE untuk analisis sirkuit elektronik, Prospector digunakan di bidang geologi untuk membantu mencari dan menemukan deposit, FOLIO digunakan untuk membantu memberikan keputusan bagi seorang manajer dalam masalah stok dan investasi, DELTA dipakai untuk pemeliharaan lokomotif listrik diesel, dan sebagainya.

\section{Struktur Sistem Pakar}

Adapun definisi Struktur Sistem Pakar dua bagian penting dari sistem pakar, yaitu lingkungan pengembangn (development environment) dan lingkungan konsultasi (consultation environment). Lingkungan pengembangan digunakan oleh pembuat sistem pakar untuk membangun komponenkomponennya dan memperkenalkan pengetahuan kedalam knowledge base (basis pengetahuan). Lingkungan konsultasi digunakan oleh pengguna untuk berkonsultasi sehingga pengguna mendapatkan pengetahuan dan nasihat dari sistem pakar layaknya berkonsultasi dengan seorang pakar (Sutojo.T, Mulyanto, Edy, Suhartono, 2011, p. 166).

Komponen-komponen Sistem Pakar

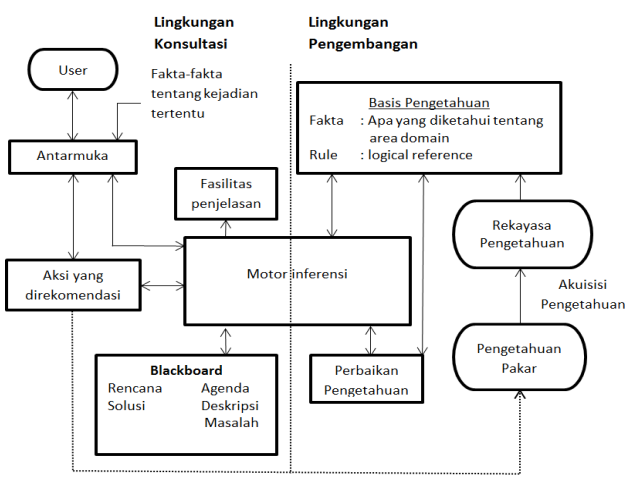

Gambar 1. Komponen-komponen sistem pakar Sumber: (Sutojo.T, Mulyanto, Edy, Suhartono, 2011, p. 167)

Keterangan;

1. Akuisisi Pengetahuan Subsistem ini digunakan untuk memasukkan pengetahuan dari seorang pakar dengan cara merekayasa pengetahuan agar bisa diproses oleh komputer dan menaruhnya kedalam basis pengetahuan dengan format tertentu (dalam bentuk representasi pengetahuan). Sumber- sumber pengetahuan bisa diperoleh dari pakar, buku, dokumen multimedia, basis data, 
laporan riset khusus, dan informasi yang terdapat di web.

2. Basis pengetahuan (Knowledge Base) Basis pengetahuan mengandung pengetahun yang diperlukan untuk memahami memformulasikan, dan menyelesaikan masalah. Basis pengetahuan terdiri Dari dua elemen dasar, yaitu;

a. Fakta, misalnya situasi, kondisi, atau permasalahan yang ada.

b. Rule (Aturan), untuk mengarahkan penggunaan pengetahuan dalam memecahkan masalah.

3. Mesin Inferensi (Inference Engine) Mesin inferensi adalah sebuah program yang berfungsi untuk memandu proses penelaran terhadap suatu kondisi berdasarkan pada basis pengetahuan yang ada, memanipulasi dan mengarahkan kaidah, model, dan fakta yang disimpan dalam basis pengetahuan untuk mencapai solusi atau kesimpulan. Dalam prosesnya, mesin inferensi menggunakan strategi pengendali, yaitu strategi yang berfungsi sebagai panduan arah dalam melakukan proses penalaran. Ada tiga teknik pengendalian yang digunakan, yaitu forward chaining, backward chaining, dan gabungan dari kedua teknik tersebut.

4. Daerah Kerja (Blackboard)Untuk merekam hasil sementara yang akan dijadikan sebagai keputusan dan untuk menjelaskan sebuah masalah yang sering terjadi, sistem pakar membutuhkan Blackboard, yaitu area pada memori yang berfungsi sebagai basis data.

5. Antarmukan Pengguna (User Interface) Digunakan sebagai media komunikasi antara pengguna dan sistem pakar. Komunikasi ini paling bagus bila disajikan dalam bahasa alami (natural language) dan dilengkapi dengan grafik, menu, dan formulir elektronik. Pada bagian ini akan terjadi dialong antara sistem pakar dan pengguna.

6. Sub sistem Penjelasan Berfungsi memberi penjelasan kepada pengguna, bagaimana suatu kesimpulan dapat diambil. Kemampuan seperti ini sangat penting bagi pengguna untuk mengetahuai proses pemindahan keahlian pakar maupun dalam pemecahan masalah.

7. Sistem Perbaikan Pengetahuan Kemampuan memperbaiki pengetahuan (Knowledge Refining System) dari seorang pakar diperlukan untuk menganalisis pengetahuan, belajar dari kesalahan masa lalu, kemudian memperbaiki pengetahuannya sehingga dapat dipakai pada masa mendatang. Kemampuan evaluasi diri seperti itu diperlukan oleh program agar dapat menganalisis alasanalasan kesuksesan dan kegagalannya dalam mengambil keputusan.

8. Pengguna (User)Pada umumnya pengguna sistem pakar bukanlah seorang pakar (nonexpert)-yang membutuhkan solusi, saran, atau penelitian (training) dari bergabagai permasalah yang ada.

\section{Forward Chaining (Runut Maju)}

Forward Chainig adalah teknik pencarian yang dimulai dengan fakta yang diketahuai kemudian mencocokkan faktafakta tersebut dengan bagian $I F$ dan $I F$ THEN. Bila ada fakta yang cocok dengan bagian $I F$, maka rule tersebut dieksekusi. Bila sebuah rule dieksekusi, maka sebuah fakta baru (bagian-THEN) ditambahkan kedalam database. Setiap kali pencocokan, dimulai dari rule teratas. Setiap rule hanya boleh dieksekusi sekali saja. Proses pencocokan 
berhenti bila tidaka ada lagi rule yang bisa dieksekusi (Hartati, Sri, Iswanti, 2008, p. 45).

\section{METODE}

\section{Analisis Kebutuhan}

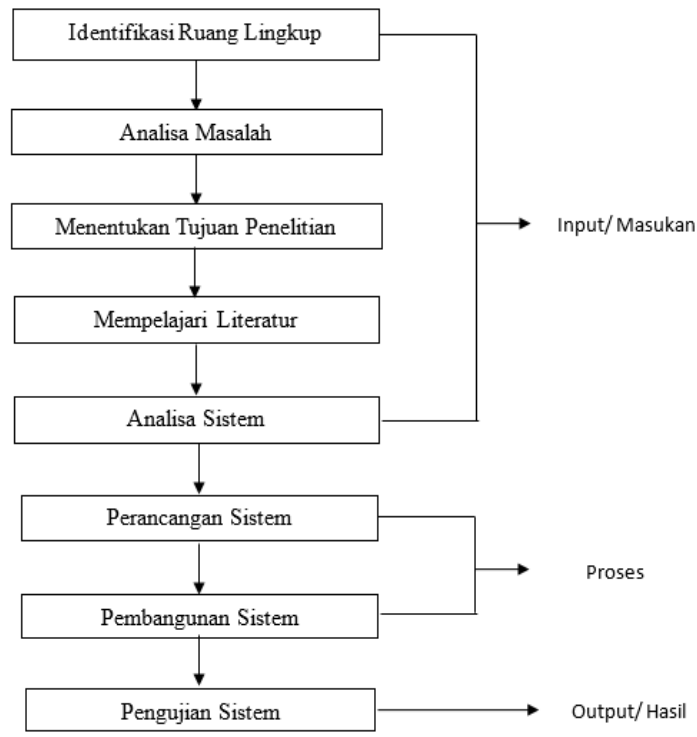

1. Ruang Lingkup Indentifkasi ruang lingkup adalah menentukan batasan-batasan dari masalah yang diteliti. Identifikasi ruang lingkup bertujuan untuk menjaga konsistensi dari penelitian ini lebih terarah, sehingga tujuan dari penelitian yang diharapkan tercapai.

2. Analisis masalah Setelah mengetahui ruang lingkup maka selanjutnya yang dilakukan adalah menganalisis masalah dimana setelah menentukan masalah atau variabel yang akan di teliti maka perlu adanya menganalisis variabel tersebut apakah layak untuk dilakukannya penelitian pada masalah tersebut.

3. Menentukan Tujuan PenelitianPeneliti menentukan tujuan penelitian yaitu mengetahui bagaimana sistem pakar untuk masalah kepribadian dramatik menggunakan metode forward chaining berbasis web.

4. Mempelajari Literatur Untuk mendukung jalannya penelitian, peneliti mempelajari sumber-sumber pengetahuan berupa bukubuku teori, jurnal-jurnal penelitian, dan sumber pustaka otentik lainnya yang berkaitan dengan penelitian, diantaranya yaitu kecedasan buatan, sistem pakar, PHP, MySQL, dan UML.

5. Pengumpulan Data Pengumpulan data dilakukan guna untuk mendapatkan rincian tentang variabel yang di ambil untuk di teliti supaya memperlengkap informasi yang dikumpulkan, dan dalam penelitian ini teknik pengumpulan data menggunakan wawancara sebagai alat untuk mendapatkan data yang diperlukan.

6. Analisis Sistem memasuki perancangan sistem penulis harus menganalisis sistem terlebih dahulu untuk mengetahui kelemahan, kekuatan dan peluang dan memperbaikinya.

7. Perancangan Sistem Perancangan sistem merupakan bagian dari merancang web dari sistem pakar yang menggunakan metode forward chaining agar dapat menentukan masalah kepribadian dramatik sesuai dengan rule yang sudah ada.

8. Pembangunan Sistem yang timbul dan membangun suatu sistem untuk dapat memenuhi kebutuhan Suatu proses atau selengkap prosedur yang harus diikuti untuk menganalisis yang timbul dan membangun suatu sistem untuk dapat memenuhi kebutuhan tersebut.

9. Pengujian Sistem Proses ini bertujuan untuk meminimalisir kesalahan dan memastikan keluaran yang dihasilkan sesuai dengan yang diinginkan. Pengujian dilakukan dengan menggunakan salah satu pendekatan pengujian untuk validasi yaitu black-box testing. 


\section{HASIL}

\section{Hasil Penelitian}

Hasil penelitian ini berupa sistem pakar untuk masalah kepribadian dramatik menggunakan metode forward chaining berbasis web.

\section{Halaman Menu User}

Dalam halaman menu user akan ditampilkan halaman menu yang dapat diakses oleh user. Adapun halaman menu tersebut adalah sebagai berikut:

\section{a. Halaman Menu Depan}

Halaman pada menu depan ini merupakan tampilan awal saat progam dijalankan, dimana dalam menu depan ini terdapat judul dan link menuju ke halaman lainnya.

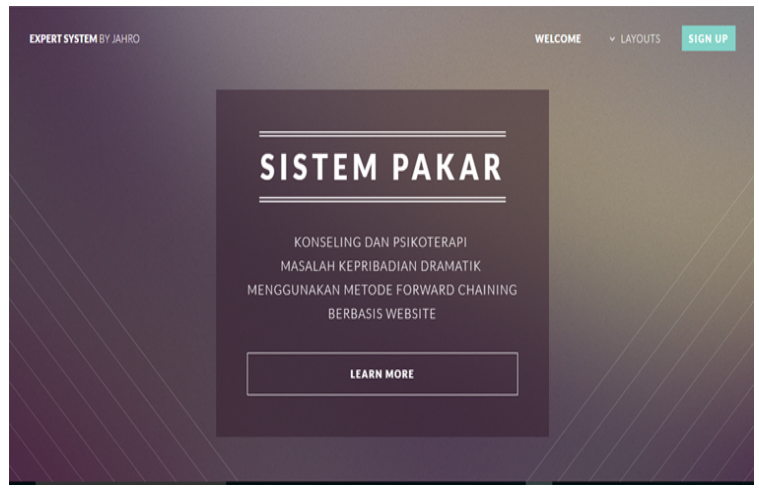

Gambar 3. Halaman Menu Depan

Sumber: Data Penelitian, 2017

\section{b. Halaman Menu Intro}

Menu ini menjelaskan sedikit tentang pengertian kepribadian dramatik, latar belakang, sistem pakar, identifikasi masalah, tujuan dan manfaat Penelitian, adapun desain halamannya sebagai berikut:

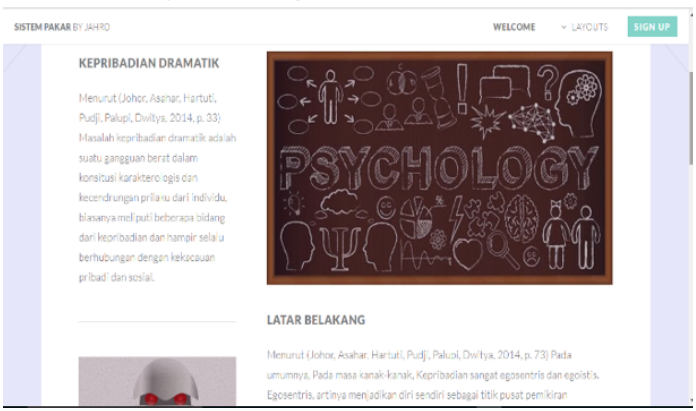

Gambar 5. Halaman Menu Into

Sumber: Data Penelitian, 2017

\section{c. Halaman Menu About Us}

Menu pada menu About Us ini menjelaskan riwayat pakar dan tempat lembaga konsultasi, riwayat hidup penulis, seperti nama dan Universitas, adapun desain halamannya sebagai berikut:

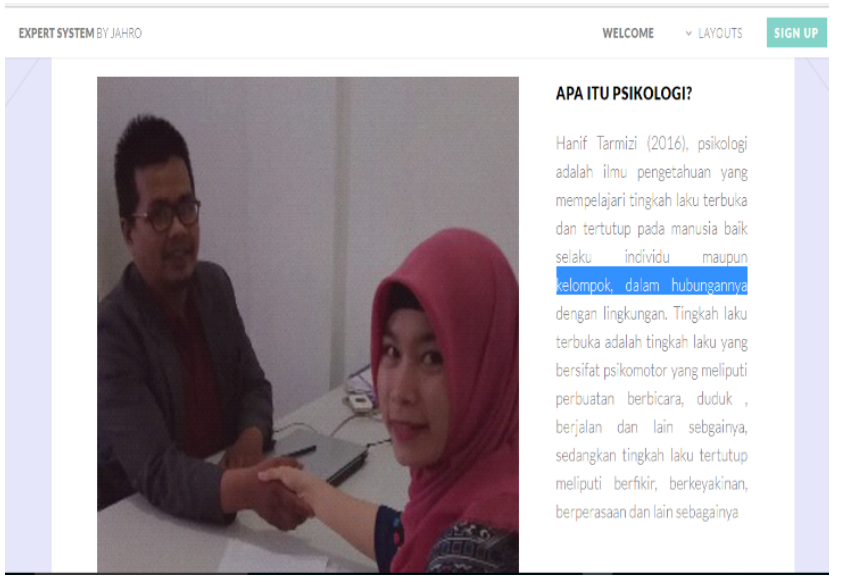

Gambar 6. Halaman Menu About As Sumber: Data Penelitian, 2017

\section{d. Halaman Menu Consultation}

Menu ini adalah menu sebelum melakukan konsultasi diharapkan user mengisi Form yang telah disediakan dibawah, guna sebagai bahan dokumentasi.

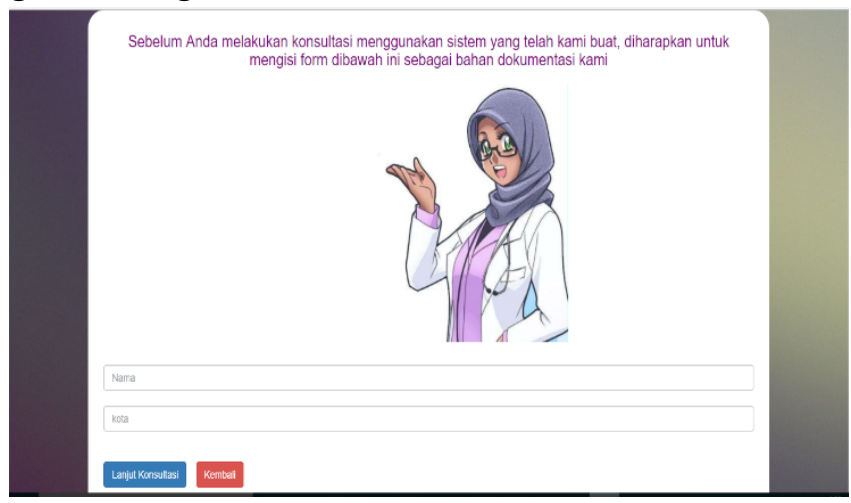

Gambar 7. Halaman Menu Consultation

Sumber: Data Penelitian, 2017

e. Halaman Consultation Sistem pakar 
Halaman ini berisikan pertanyaan tentang gejala-gejala yang diberikan sistem dan pengguna akan menjawab Benar atau Tidak sehingga sistem dapat menganalisa kasus tersebut

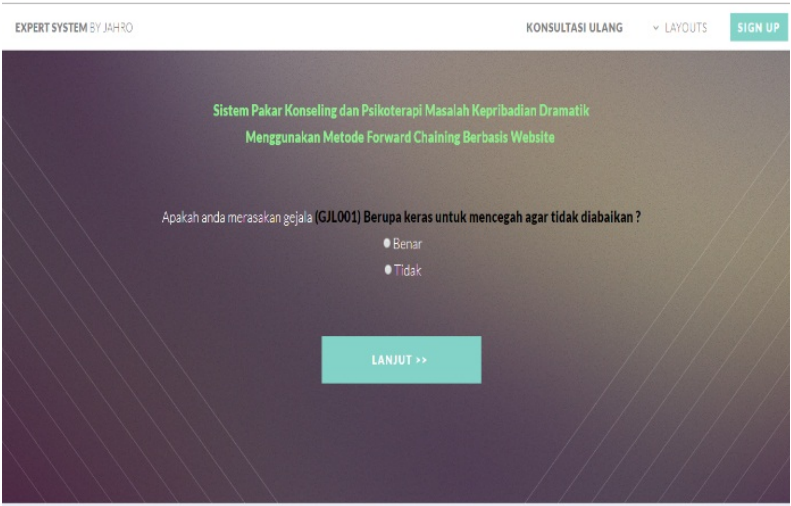

Gambar 8. Halaman Consultation Sistem pakar

Sumber: Data Penelitian, 2017

\section{f. Halaman Analisis Sistem Pakar}

Halaman ini berisikan hasil analisa ataupun diagnosa sistem pakar berdasarkan dari jawaban yang diinput pengguna, maka sistem akan melakukan proses penelusuran dan menampilkan hasilnya pada halaman Hasil Diagnosa. adapun desainnya sebagai berikut:

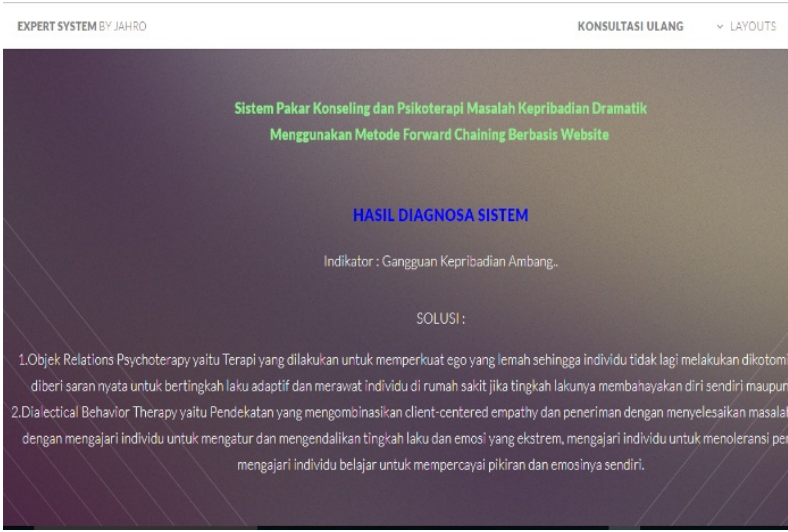

Gambar 9. Halaman Analisis Sistem Pakar

Sumber: Data Penelitian, 2017

\section{g. Halaman Menu Advice}

Menu ini berisikan tentang komentar dan saran pengguna setelah menggunakan sistem pakar, adapun desainnya sebagai berikut:

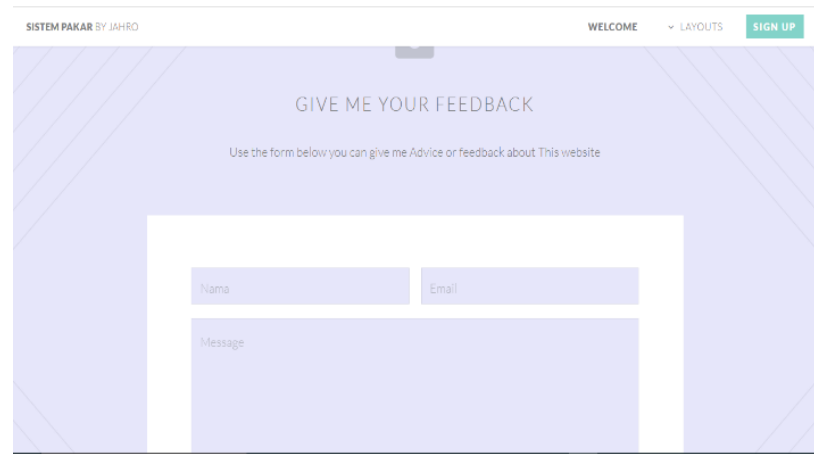

Gambar 10. Halaman Menu Advice

Sumber: Data Penelitian, 2017

\section{h. Menu Sign up}

Dalam menu sign up ini akan ditampilkan halaman- halaman yang dapat diakses oleh admin. Adapun menu tersebut adalah sebagai berikut :

\section{Halaman Form Login Admin}

Halaman ini digunakan apabila admin masuk ke halaman utama administrator dengan memasukkan username dan password yang sesuai, adapun desainnya sebagai berikut:

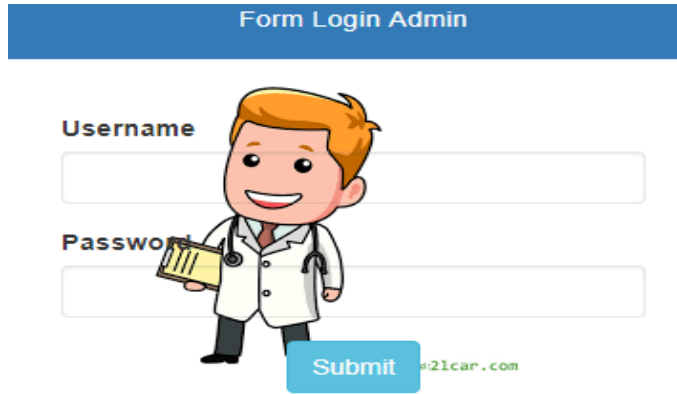

Gambar 11. Halaman Form Login Admin Sumber: Data Penelitian, 2017

\section{Halaman Utama Admin}

Pada halaman utama Admin ini merupakan tampilan awal, dimana dalam menu depan ini terdapat dan link menuju ke halaman lainnya. 


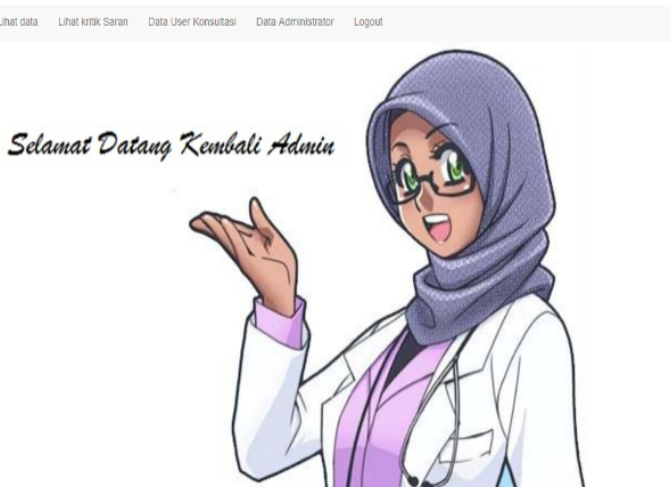

Gambar 12. Halaman Utama Admin

Sumber: Data Penelitian, 2017

\section{Menu Lihat Data}

Menu lihat data ini berisi basis data yang bisa ditambah, edit dan delete oleh admin, adapun desainnya sebagai berikut:

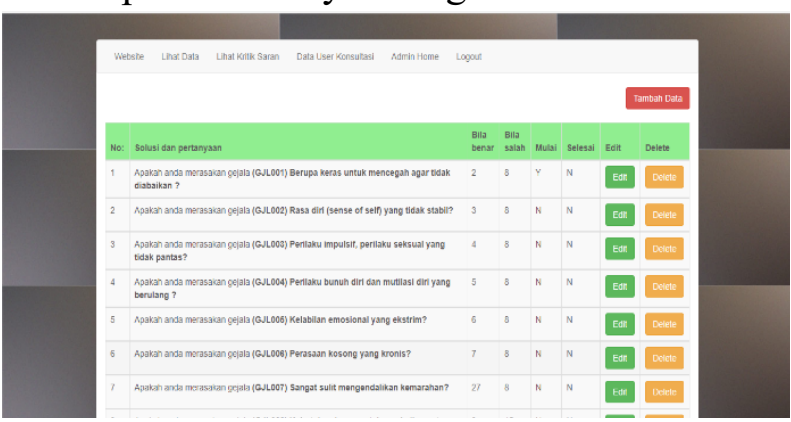

Gambar 13. Menu Lihat Data

Sumber: Data Penelitian, 2017

\section{Menu Tambah Data}

Halaman ini berfungsi memasukkan datadata baru dalam basis pengetahuan sistem pakar, sebagai berikut:

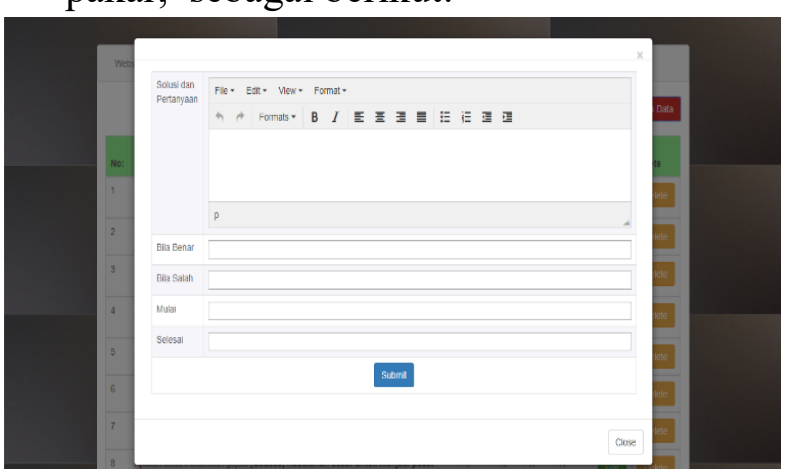

Gambar 14. Menu Tambah Data

Sumber: Data Penelitian, 2017

\section{Menu Edit Data}

Menu ini berfungsi merubah data-data dalam basis pengetahuan sistem pakar, sebagai berikut:

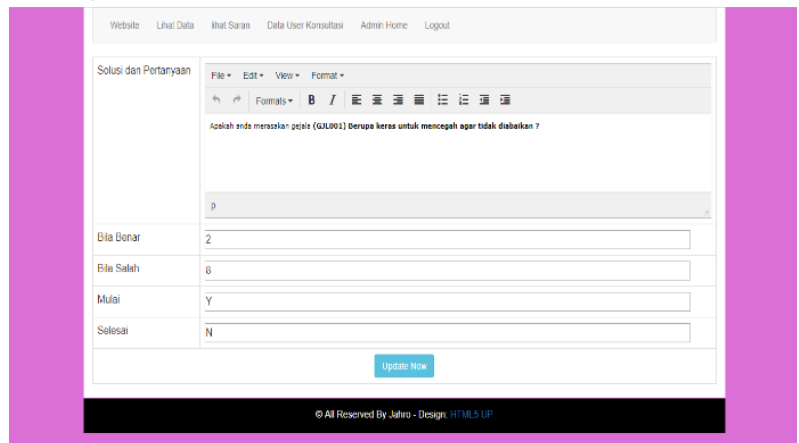

Gambar 15. Menu Edit Data

Sumber: Data Penelitian, 2017

\section{Menu Lihat Kritik dan Saran}

Menu ini berfungsi melihat kritik dan saran pengguna setela menggunakan sistem pakar, adapun desainnya sebagai berikut:

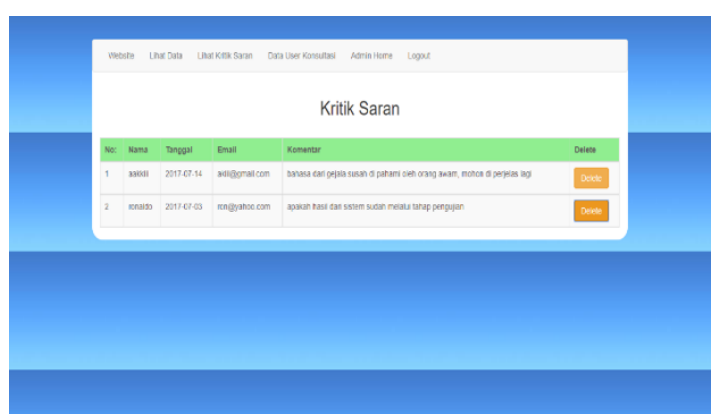

Gambar 16. Menu Lihat Kritik dan Saran Sumber: Data Penelitian, 2017

\section{Menu Data User Konsultasi}

Menu ini berfungsi melihat siapa saja yang telah mengakses sistem pakar, adapun desainnya sebagai berikut:

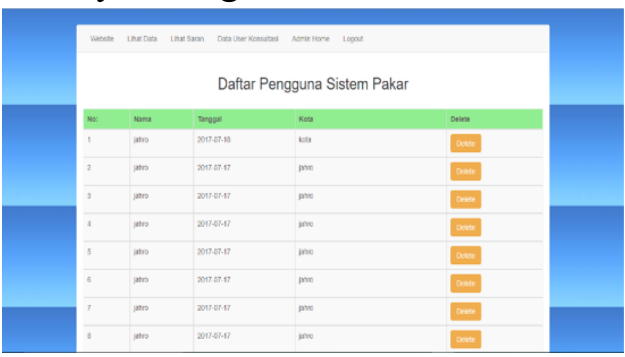

Gambar 17. Menu User Konsultasi 
Sumber: Data Penelitian, 2017

6. Menu Data Administrator

Menu ini berfungsi untuk menambah admin baru yang bisa mengakses lebih dari satu admin, adapun desainnya sebagai berikut:

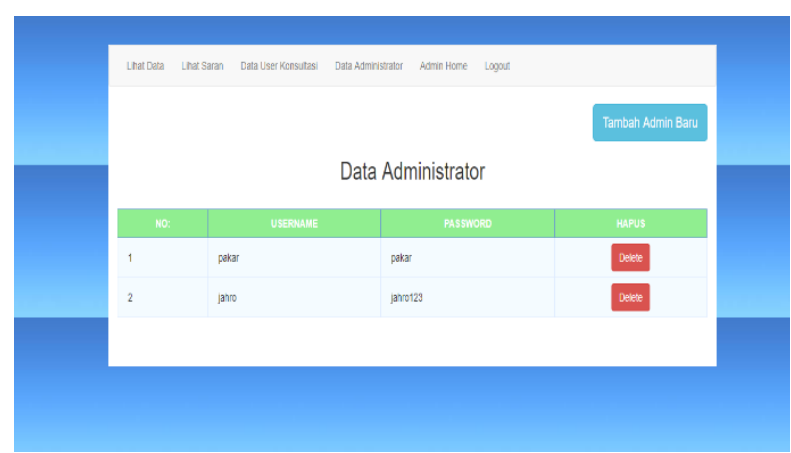

Gambar 18. Menu Data Administrator

Sumber: Data Penelitian, 2017

\section{Menu Log out}

Log Out digunakan oleh Admin atau pakar ketika hendak keluar dari Menu from Login setelah selesai mengelola data-data yang ada di dalamnya lalu sistem akan mengarahkan Admin atau pakar kembali ke menu utama.

\section{Pembahasan}

Pembahasan yang dijelaskan dalam penelitian ini adalah pengujian terhadap sistem untuk membuktikan apakah sistem telah berfungsi dengan baik pada saat digunakan untuk masalah kepribadian dramatik. Pengujian dilakukan dengan 2 cara yaitu pengujian validasi sistem menggunakan black-box testing dan pengujian dengan membandingkan hasil diagnosa sistem dengan hasil diagnosa pakar.

\section{Pengujian Validasi Sistem}

Pada bab ini akan dibahas mengenai pengujian terhadap sistem pakar yang telah dibuat. Adapun metode pengujiannya menggunakan metode white box testing.
Pengujian white box testing adalah pengujian yang didasarkan pada pengecekan terhadap detail perancangan, menggunakan struktur kontrol dari desain program secara procedural untuk membagi pengujian ke dalam beberapa kasus pengujian. Secara sekilas dapat diambil kesimpulan white box testing (Silvia, Leonita, Virginia, Candra, \& Sevani, 2015).

\section{Pengujian Rule Sistem Pakar}

Pengujian ini dilakukan untuk mencari kesalahan rule atau kaidah pada sistem pakar yang telah dibuat dan dirangkum dalam dalam bentuk table dibawah ini:

Tabel 1. Tabel Pengujian Rule Sistem pakar

\begin{tabular}{|c|c|c|}
\hline Kasus/Gejala & Hasil Analisis & Hasil Harapan \\
\hline $\begin{array}{l}\text { IF,GJL001,GJ002,GJ003,GJ0 } \\
\text { 04,GJL005,GJL006,GJ007 }\end{array}$ & $\begin{array}{l}\text { Gangguan kepribadian } \\
\text { ambang }\end{array}$ & $\begin{array}{l}\text { Gangguan kepribadian } \\
\text { ambang }\end{array}$ \\
\hline $\begin{array}{l}\text { IF,GJ_008,GJ009,GJ010,GJ0 } \\
11, G J 012, G J 013, G J 0014\end{array}$ & $\begin{array}{l}\text { Gangguan kepribadian } \\
\text { histrionik }\end{array}$ & $\begin{array}{l}\text { Gangguan kepribadian } \\
\text { histrionik }\end{array}$ \\
\hline $\begin{array}{l}\text { IF,GJL15,GJ016,GJ017,GJ0 } \\
\text { 8,GJ019 }\end{array}$ & $\begin{array}{l}\text { Gangguan kepribadian } \\
\text { narsistik }\end{array}$ & $\begin{array}{l}\text { Gangguan kepribadian } \\
\text { narsistik }\end{array}$ \\
\hline $\begin{array}{l}\text { IF,GJL020,GJ021,GJ022,GJ0 } \\
\text { 23,GJL024,GJL25,GJ026 }\end{array}$ & $\begin{array}{l}\text { Gangguan kepribadian } \\
\text { antisosial }\end{array}$ & $\begin{array}{l}\text { Gangguan kepribadian } \\
\text { antisosial }\end{array}$ \\
\hline
\end{tabular}

Sumber: Data Penelitian, 2017

\section{Membandingkan Hasil Analisa Sistem dengan Hasil Analisa Pakar}

Ada sebanyak 11 gejala yang peneliti bandingkan, agar sistem dapat menganalisa sesuai analisa pakar yang sesungguhnya, antara lain;

1. Kasus 1/ Gejala

- Berupa keras untuk mencengah agar tidak diabaikan.

- Rasa diri (sense of self) yang tidak stabil.

- Perilaku impulsif, perilaku seksual yang tidak pantas.

- Perilaku bunuh diri dan mutilasi diri yang berulang. 
- Kelabilan emosional yang ekstrim.

- Perasaan kosong yang kronis.

- Sangat sulit mengendalikan kemarahan.

Tabel 2. Perbandingan hasil analisis sistem pakar dengan hasil pakar

\begin{tabular}{ll}
\hline Hasil Analisis & Hasil Analisis \\
Sistem Pakar & Pakar \\
\hline Gangguan & Gangguan \\
kepribadian ambang & $\begin{array}{l}\text { kepribadian } \\
\text { ambang }\end{array}$ \\
\hline
\end{tabular}

Sumber: Data Penelitian, 2017

3 Kasus 2/ Gejala

a. Terfokus pada kebersihan, kecerdasan dan kecantikan diri.

b. Kebutuhan yang paling keras untuk dipuji.

c. Perasaan kuat bahwa mereka berhak mendapatkan segala sesuatu.

d. Kecenderungan memanfaatkan orang lain.

e. Iri pada orang lain.

Tabel 3. Perbandingan hasil analisis sistem pakar dengan hasil pakar

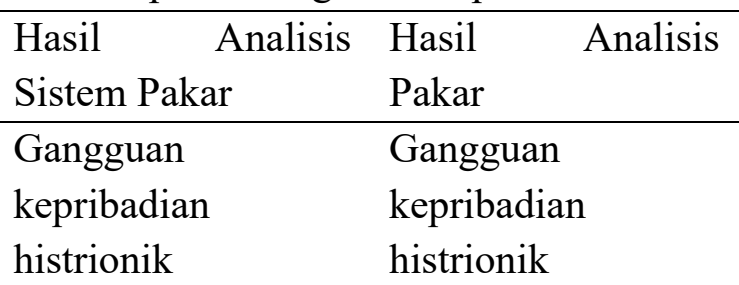

Sumber: Data Penelitian, 2017

\section{Kasus 3/ Gejala}

1. Kebutuhan besar untuk menjadi pusat perhatian.

2. Perubahan ekspresi emosi secara scepat.

3. Memanfaatkan penampilan fisik untuk menarik perhatian orang lain pada dirinya.
4. Bicaranya sangat tidak tepat.

5. Ekspresi emosional yang berlebihan.

6. Sangat mudah memberi pengaruh pada orang lain.

7. Menyalahartikan hubungan sebagai lebih intim dari yang sebenarnya.

Tabel 4. Perbandingan hasil analisis sistem pakar dengan hasil pakar

\begin{tabular}{ll}
\hline Hasil Analisis & Hasil Analisis \\
Sistem Pakar & Pakar \\
\hline Gangguan & Gangguan \\
kepribadian & kepribadian \\
narsistik & narsistik \\
\hline
\end{tabular}

Sumber: Data Penelitian, 2017

5 Kasus 4/Gejala

a. Berulang kali melangggar hukum.

b. Menipu, berbohong.

c. Mudah tersinggung dan agresif.

d. Tidak memperdulikan keselamatan diri sendiri dan orang lain.

e. Tidak bertanggung jawab terhadap pekerjaan.

f. Kurang memiliki rasa penyesalan.

g. Kondisi keluarga yang tidak harmonis.

Tabel 4. Perbandingan hasil analisis sistem pakar dengan hasil pakar

\begin{tabular}{ll}
\hline Hasil Analisis & Hasil Analisis \\
Sistem Pakar & Pakar \\
\hline Gangguan & Gangguan \\
kepribadian & kepribadian \\
antisosial & antisosial \\
\hline
\end{tabular}

Sumber: Data Penelitian, 2017

Dari perbandingan hasil analisa sistem pakar dengan hasil analisa seorang pakar sesungguhnya tidak ada kasus yang berbeda, didapatkan hasil yang baik. Sebanyak 4 kasus 
yang dibandingkan. Hal ini bukan disebabkan karena analisa Maka berdasarkan pengujian perbandingan sistem pakar ini teruji sangat akurat, memiliki tingkat kesamaan dengan pakar sesungguhnya sebesar $100 \%$.

\section{Pengujian Kesalahan Program}

Pengujian ini dilakukan untuk mencari kesalahan koding program pada setiap menu-menu pada sistem yang disebabkan oleh kesalahan penulisan program, kegiatan ini disebut juga debugging.

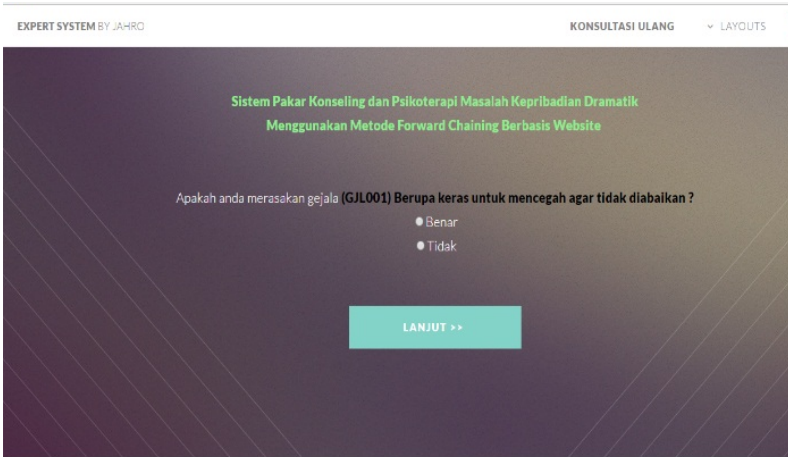

Gambar 19. Contoh kode peringatan kesalahan pada proses debugging

Sumber: Data Penelitian, 2017

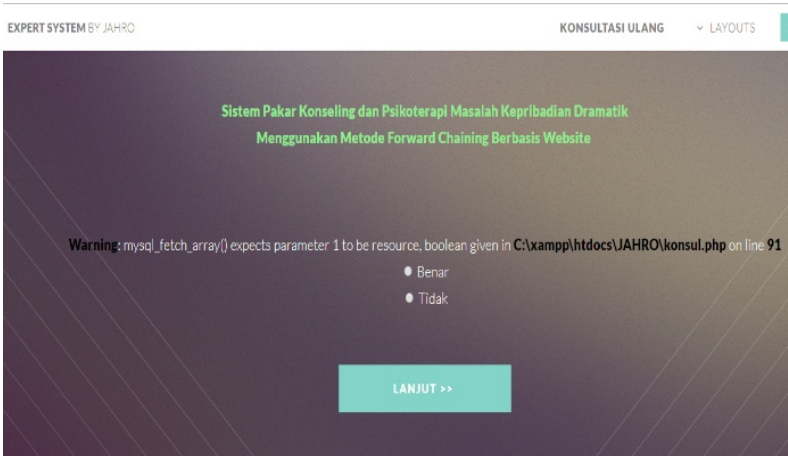

Gambar 20. Contoh kode peringatan kesalahan pada proses debugging

Sumber: Data Penelitian, 2017

Tabel 5. Tabel Pengujian Kesalahan Program

\begin{tabular}{|c|c|c|c|}
\hline No & Pengujian & & $\begin{array}{l}\text { Hasil } \\
\text { Pengujian }\end{array}$ \\
\hline 1. & $\begin{array}{l}\text { Interface } \\
\text { Depan }\end{array}$ & Halaman & $\mathrm{OK}$ \\
\hline
\end{tabular}

\begin{tabular}{|c|c|c|}
\hline 2. & Interface Menu Intro & $\mathrm{OK}$ \\
\hline 3. & $\begin{array}{l}\text { Interface } \\
\text { About Us }\end{array}$ & $\mathrm{OK}$ \\
\hline 4. & $\begin{array}{l}\text { Interface } \\
\text { Consultation }\end{array}$ & $\mathrm{OK}$ \\
\hline 5. & $\begin{array}{l}\text { Interface Halaman } \\
\text { Consultation } \\
\text { pakar }\end{array}$ & $\mathrm{OK}$ \\
\hline
\end{tabular}

6. Interface Menu $\mathrm{OK}$

Advice

7. Interface Halaman OK

Form Login Admin

8. Interface Menu Lihat $\mathrm{OK}$

Data

\begin{tabular}{lll}
\hline 9. & $\begin{array}{l}\text { Interface } \\
\text { Tambah Data }\end{array}$ \\
\hline 10 & $\begin{array}{l}\text { Interface Interface } \\
\text { Menu Edit Data }\end{array}$ & OK \\
\hline 11 & $\begin{array}{l}\text { Interface Menu Lihat } \\
\text { Kritik dan Saran }\end{array}$ \\
\hline 12 & $\begin{array}{l}\text { Interface Menu Data } \\
\text { OKer Konsultasi }\end{array}$ \\
\hline 13 & $\begin{array}{l}\text { Interface Menu Data } \\
\text { Administrator }\end{array}$ \\
\hline
\end{tabular}

Sumber: Data Penelitian, 2017

\section{KESIMPULAN}

Berdasarkan penelitian dan perancangan sistem yang dilakukan maka dapat ditarik kesimpulan yaitu:

1. Metode forward chaining dapat diterapkan dalam sistem pakar untuk mendiagnosa masalah kepribadian dramatik berbasis web.

2. Sistem admin dapat melakukan proses penambahan, penghapusan dan ubah data untuk masalah kepribadian dramatik tertentu.

3. Sistem pakar yang dibangun ini memudahkan masyarakat umum untuk 
mengetahui gejala-gejala masalah kepribadian dramatik.

\section{DAFTAR PUSTAKA}

[1] A.s, Rosa, S. (2011). Rekayasa Perangkat Lunak. Bandung.

[2] Aditya, Nur, A. (2010). Jago php\& MySql (1st ed.). Bekasi.

[3] Andreyana, P. V., Piarsa, I. N., \& Buana, P. W. (2015). Sistem Pakar Analisis Kepribadian Diri dengan Metode Certainty Factor. MERPATI, 3(2), 78-86.

[4] Asahar Johar1, Pudji Hartuti2, D. D. P., \& 1, 2, 3Program. (2014). Implementasi metode frame untuk mendiagnosa gangguan kepribadian dramatik menggunakan sistem pakar, 2(November), 72-80.

[5] Dewi Miranti Wijayal Wahyu Kusuma Raharja2. (2015). IMPLEMENTASI METODE FORWARD CHAINING PADA SISTEM PAKAR PENENTUAN KARAKTER DIRI BERBASIS WEBSITE, 6.

[6] Drs. Asahar Johar, M. Si, Desty Dwitia Palupi, S. T. (2011). IMPLEMENTASI METODE FRAME UNTUK MENDIAGNOSA GANGGUAN KEPRIBADIAN DRAMATIK MENGGUNAKAN SISTEM PAKAR, (Snati), 17-18.

[7] Ghaemian, A., \& Abdi, S. (2013). Symptoms of Cluster B Personality Disorders in Iranian Females Wearing Thick Makeup: A case-control Study. Procedia - Social and Behavioral Sciences, $\quad 84, \quad 686-690$. https://doi.org/10.1016/j.sbspro.2013.06. 627

[8] Hartati, Sri, Iswanti, S. (2008). Sistem Pakar Pengembangan (Pertama). Yogyakarta.
[9] Heidari, S., \& Mahmood, M. (2015). Comparative Evaluation of Cognitive Emotion Regulation between "B " Personality Disorders and Normal Persons. Procedia - Social and Behavioral Sciences, 185, 54-60. https://doi.org/10.1016/j.sbspro.2015.03. 434

[10]Ignas. (2016). Webmaster Series. Semarang.

[11]Kurniawan, R. (2010). Php Dan MySql Untuk Orang awam (2nd ed.). Palembang.

[12]Kusrini. (2008). Aplikasi Sistem Pakar. (D. Prabantini, Ed.) (1st ed.). Yogyakarta. [13]Madcom. (2016). Pemrograman PHP dan MySql Untuk Pemula (1st ed.). Yogyakarta.

[14]Nasir, Abdul, Muhith, A. (2011). DasarDasar Keperawatan Jiwa. jakarta.

[15]Nursalim, M. (2015). pengembangan Profesi Bimbingan Konseling. (N. Dwiasri, Mutiara, Oktaviani, Sallama.T, Ed.). jakarta.

[16]Pangerap, Ritha, O. (2009). ANALISIS PERLAKUAN AKUNTANSI UNTUK WEBSITE PADA PT. BANK SULUT (PERSERO) MANADO, 1(3), 761-770.

[17]Saputra, A. (2012). Php, Html5 dan CSS3. Jakarta.

[18] Silvia, Leonita, C., Virginia, Candra, Y. J., \& Sevani, N. (2015). Aplikasi Diagnosis Karies pada Gigi Manusia Berbasis Web. Ultimatics, VII (No. 1), 43-49.

[19] Sudaryono. (2015). Metodologi Riset Di Bidang TI. (N. WK, Ed.). yogyakarta.

[20] Sugiyono. (2012). Metode Penelitian Kuantitatif Kualitatif Dan $R \& D$. bandung. 
[21] Sutojo.T, Mulyanto, Edy, Suhartono, V. (2011). Kecerdasan Buatan (1st ed.). yogyakarta.

[22]Taufik, I. (2014). APLIKASI DIAGNOSA GANGGUAN KEPRIBADIAN, 2.

[23] Wulandari, F., Syafria, F., \& Syafriandi, M. (2015). Penerapan Fuzzy Multi Criteria Decision Making untuk Diagnosa Awal Gangguan Jiwa dengan Metode Agregasi, 1(2), 63-66. 